\title{
Zero valent iron enhances methane production from primary sludge in anaerobic digestion
}

Wei Wei ${ }^{\text {a,d }}$, Zhengqing Cai ${ }^{\mathrm{b}}$, Jie Fu ${ }^{\mathrm{c}}$, Guo-Jun Xie ${ }^{\mathrm{d}}$, Ang Li ${ }^{\mathrm{d}}, \mathrm{Xu}$ Zhou ${ }^{\mathrm{e}}$, Bing-Jie Ni ${ }^{\text {a }}$, Dongbo Wang $^{\mathrm{f}, *}$, Qilin Wang ${ }^{\mathrm{a}, \mathrm{g}, *}$

${ }^{a}$ Advanced Water Management Centre, The University of Queensland, QLD 4072, Australia

${ }^{\mathrm{b}} \mathrm{School}$ of Resource and Environmental Engineering, East China University of Science and Technology, Shanghai 200237, China

${ }^{c}$ Department of Environmental Science and Engineering, Fudan University, Shanghai 200438, China

${ }^{\mathrm{d}}$ State Key Laboratory of Urban Water Resource and Environment, Harbin Institute of Technology, 150090 Harbin, China

${ }^{\mathrm{e}}$ Shenzhen Engineering Laboratory of Microalgal Bioenergy, Harbin Institute of Technology (Shenzhen), Shenzhen 518055, China

${ }^{\mathrm{f}}$ College of Environmental Science and Engineering, Hunan University, and Key Laboratory of Environmental Biology and Pollution Control, Ministry of Education, Hunan University, Changsha 410082, China

${ }^{\mathrm{g}} \mathrm{School}$ of Engineering and Built Environment \& Centre for Clean Environment and Energy \& Environmental Futures Research Institute, Griffith University, QLD 4111, Australia

*Corresponding authors.

E-mail: qilin.wang@ griffith.edu.au (Q. Wang); Tel.: +61 737355036

E-mail: w.dongbo@yahoo.com (D. Wang) 
ABSTRACT: This study proposed a novel zero valent iron (ZVI) technology to enhance anaerobic methane production from primary sludge in the anaerobic digester and to improve the dewaterability of digested sludge for the first time. Compared to the control test without ZVI, the anaerobic digester with ZVI at all levels (1, 4 and $20 \mathrm{~g} / \mathrm{L})$ played a driving role in anaerobic methane production from primary sludge. The maximal biochemical methane production of $439 \pm 5$ $\mathrm{L} \mathrm{CH}_{4} / \mathrm{kg}$ VS was achieved at ZVI of $4 \mathrm{~g} / \mathrm{L}$, while only $345 \pm 2 \mathrm{~L} \mathrm{CH}_{4} / \mathrm{kg}$ VS (volatile solids) was produced in the case of no-ZVI dosage, representing a relative increase of $26.9 \pm 0.1 \%$. It was also found that ZVI addition would produce an anaerobically digested sludge with a better dewaterability, as indicated by the decrease of the normalized capillary suction time from 100 to 63 89 s, respectively. Model based analysis revealed that the enhanced methane production from primary sludge was due to an increase in both hydrolysis rate and biochemical methane potential of primary sludge. Economic analysis demonstrated that ZVI technology was economically favorable.

Keywords: Anaerobic digestion; Zero valent iron; Primary sludge; Methane production; Dewaterability 


\section{Introduction}

Wastewater treatment plants (WWTPs) are expanding rapidly to serve the growing demands for cities, which has brought about an increase of sludge production [1]. The disposal of sludge produced in wastewater treatment is costly. In Australia, for example utilities pay some $\$ 30 \sim 150$ per wet ton of sludge disposed of. In some cases, the costs are even higher [2, 3]. Therefore, sludge management is regarded as a major concern in wastewater treatment today. Sludge is normally treated biologically to stabilise and improve subsequent dewatering, and anaerobic digestion is extensively applied as an approach to do this and obtain renewable energy in the form of methane gas $[4,5]$. However, anaerobic digestion is often limited by the slow hydrolysis rate and poor biochemical methane potential of the sludge [6]. To address these limitations, many different treatment technologies (e.g. mechanical [7], chemical [8], thermal [9] and enzymatic [10]) were previously investigated and applied. Unfortunately, most of these methods require high energy or chemical inputs, making the process costly $[1,6,11]$. Thus, alternative technologies to enhance anaerobic digestion performance of sludge are needed.

Zero-valent iron (ZVI), a low cost and metallic chemical, can be freely obtained from machinery factory. It has been proven to be able to enhance methanogenesis [12]. Also, anaerobic wastewater treatment could be improved via adding ZVI powder in anaerobic reactor. The results showed that the COD removal with the addition of ZVI was about one time higher in comparison to that without ZVI [13]. Recently, Feng et al. [14] demonstrated that adding ZVI improved both methane production and volatile solids (VS) destruction of waste activated sludge (WAS) in anaerobic digestion, with the highest improvement being approximately $43.5 \%$ (from 193 to $276 \mathrm{~mL} \mathrm{CH}_{4} / \mathrm{g}$ VSS) and $44.0 \%$ (from 27.7 to $39.9 \%$ ), respectively, achieved at the dosage of $20 \mathrm{~g} / \mathrm{L}$. This 
suggested that ZVI dosing technology as a potential treatment method was effective in enhancing WAS reduction in anaerobic digestion.

However, in existing wastewater treatment plants (WWTPs), another major sludge stream, primary sludge (PS), is often mixed and digested together with WAS [15]. The functions of ZVI in the anaerobic digestion of PS still remain unknown. Compared to WAS, PS has a much lower level of biomass and extracellular polymeric substances (EPS) but higher fatty acids content $[3,16]$. It was found that sludge characteristics have an effect on the effectiveness of sludge treatment technologies. For example, free nitrous acid (FNA, 1.0-2.0 $\mathrm{mg} \mathrm{HNO}_{2}-\mathrm{N} / \mathrm{L}$ for $24 \mathrm{~h}$ ) pretreatment technology could increase methane production from WAS [6], but inhibit methane production from PS under the same pretreatment condition [17]. This indicates that FNA pretreatment technology should be implemented solely on WAS instead of the mixture of WAS and PS. In contrast, free ammonia (FA, 420-680 $\mathrm{mg} \mathrm{NH}$ - $\mathrm{N} / \mathrm{L}$ for $24 \mathrm{~h}$ ) was effective in enhancing methane production from both WAS and PS [18, 19], indicating that FA pretreatment approach could be applied in the mixture of WAS and PS to maximize anaerobic methane production. Therefore, it is very important to unravel the effect of ZVI dosing treatment method on anaerobic digestion performance of PS. This will determine whether ZVI could be added to the PS containing anaerobic digester to enhance methane production in WWTPs.

In this study, the effect of ZVI on anaerobic digestion performance of PS was evaluated for the first time. ZVI at a series of concentrations (1, 4 and $20 \mathrm{~g} / \mathrm{L})$ was added into an anaerobic digester with no ZVI as a control. Anaerobic methane production and VS destruction were calculated and compared. The dewaterability of anaerobically digested sludge was assessed by capillary suction time. The hydrolysis rate $(\mathrm{k})$ and biochemical methane potential $\left(\mathrm{B}_{0}\right)$ of PS in anaerobic digestion with ZVI dosing were revealed through model-based analysis. Economic analysis was conducted to 
shed light on the economic potential of the ZVI treatment approach.

\section{Materials and Methods}

\subsection{Substrate and inoculums}

Both primary sludge and anaerobically digested sludge were used to conduct the tests. Primary sludge as the substrate was harvested from the primary settler of a biological nutrient removal WWTP in Brisbane, Australia. Anaerobically digested sludge as the inoculums was obtained from the mesophilic anaerobic digestion unit receiving mixed primary sludge and WAS in above WWTP. The mesophilic anaerobic digestion unit has a sludge retention time (SRT) of 15-18 d. The inoculums were employed to biodegrade primary sludge in the biochemical methane potential assays to be further described later. The main characteristics of the substrate and inoculums were summarized in Table 1.

(Position for Table 1)

\subsection{Batch anaerobic biochemical methane potential tests}

Biochemical methane productions from the anaerobic digesters with and without ZVI addition (0-20 g/L) was evaluated using biochemical methane potential (BMP) tests, as detailed in Wang et al. [6].

In each $160 \mathrm{~mL}$ serum bottle for the BMP test, $75 \mathrm{~mL}$ inoculum and $25 \mathrm{~mL}$ primary sludge with a VS-based ratio of $2.0 \pm 0.1$ were added. Afterwards, $0,1,4$ and $20 \mathrm{~g} / \mathrm{L}$ of ZVI powder with the diameter of $0.2 \mathrm{~mm}$ were added into each serum bottle, respectively. It has been demonstrated that anaerobic methane production from WAS could be enhanced by the addition of ZVI at 0-20 g/L [14]. 
Therefore, these ZVI concentrations were chosen in this work. All serum bottles were flushed with nitrogen gas for 1 min and capped with rubber stoppers with aluminium crimp caps, then mixed and placed in a constant temperature incubator $\left(35 \pm 1^{\circ} \mathrm{C}\right)$. A blank was also set up, in which equivalent volume of Milli-Q water instead of primary sludge was added and mixed with inoculum. All tests were operated in triplicates. The BMP tests lasted for 50 days to ensure the complete anaerobic digestion with insignificant levels of biogas production.

The volume and composition of produced biogas (i.e. $\mathrm{CH}_{4}, \mathrm{H}_{2}, \mathrm{~N}_{2}, \mathrm{CO}_{2}$ ) in every test were recorded every day over the first week and every $3 \sim 7$ days afterwards to determine the methane volume. After the anaerobic digestion, the mixture (i.e., anaerobically digested sludge) in each serum bottle was poured out and its dewaterability was assessed by capillary suction time (CST, an indicator of dewaterability).

\subsection{Analytical methods}

TS, VS and TCOD in sludge samples (i.e. substrate and inoculums) were measured according to Standard Methods [20]. For the SCOD measurement, the sludge sample was centrifuged (5000g, 15 min) and then filtered using a syringe filter with $0.45 \mathrm{~mm}$ pore size. $\mathrm{pH}$ value was measured using a pH meter (TPS miniCHEM).

Biogas production volume was measured with a manometer at the start of each sampling event, based on the pressure increase in the headspace of the serum bottle under standard conditions $\left(25^{\circ} \mathrm{C}\right.$, $1 \mathrm{~atm})$. Biogas composition was determined using a Perkin Elmer loop injection gas chromatograph (GC), which was fitted with a stainless steel column (Haysep at 80/100 mesh) and a GC Plus Data Station (model 1022, PerkineElmer, Waltham, MA, USA). The volume of methane was calculated by multiplying the biogas production volume by the methane percentage in biogas. The methane production volume from primary sludge was obtained by subtracting methane produced from blank 
vial. Methane production from primary sludge sample was expressed as the methane volume per kilogram of VS added ( $\mathrm{L} \mathrm{CH}_{4} / \mathrm{kg} \mathrm{VS}$ added).

Capillary suction time was measured with a capillary suction timer $\left(22 \times 16 \times 7 \mathrm{~cm}^{3}\right.$, Triton-WPRL, Type 304) based on Standard Methods [20]. The volume and temperature of samples were kept constant $\left(5 \mathrm{~mL}, 22 \pm 1{ }^{\circ} \mathrm{C}\right)$ to avoid their effect on the CST result. The dewaterability of anaerobically digested sludge was reported as CST divided by the TS content (\%) (i.e. normalized CST) in the digested sludge (s) to prevent bias among samples with different solid concentrations.

In addition, the statistical analysis was used to assess the significance of results. Herein, $\mathrm{p}<0.05$ indicates statistically significant, whereas $\mathrm{p}>0.05$ indicates statistically insignificant.

\subsection{Model Analysis}

The methane production kinetics and potential of primary sludge with and without ZVI addition in anaerobic digester were evaluated by the hydrolysis rate $(\mathrm{k})$ and biochemical methane potential $\left(\mathrm{B}_{0}\right)$. These two key parameters were estimated by fitting the experimental data of BMP assays to an one-substrate model using a modified version of Aquasim 2.1d.

Residual sum of squares between the experimental data and predicted data was the objective function [21]. The optimal set of two parameters (i.e. $\mathrm{k}$ and $\mathrm{B}_{0}$ ) will be got when the residual sum of squares is minimized. According to the objective surface searching method [21], the uncertainty surfaces of $\mathrm{k}$ and $\mathrm{B}_{0}$ were determined. The one-substrate model was shown in Eq. (1) [21].

$B(t)=B_{0}\left(1-e^{-k t}\right)$

where $\mathrm{B}(\mathrm{t})$ is biochemical methane production at $\mathrm{t}\left(\mathrm{L} \mathrm{CH}_{4} / \mathrm{kg}\right.$ VS); $\mathrm{t}$ is time $(\mathrm{d}) ; \mathrm{B}_{0}$ is biochemical methane potential $\left(\mathrm{L} \mathrm{CH}_{4} / \mathrm{kg} \mathrm{VS}\right) ; \mathrm{k}$ is hydrolysis rate $\left(\mathrm{d}^{-1}\right)$.

The VS destruction (Y) of primary sludge was determined using B(t), by Eq. (2) [22]: 
$\mathrm{Y}(\mathrm{t})=\mathrm{B}(\mathrm{t}) / 380 \times \mathrm{R}_{\mathrm{SS}}$

where $\mathrm{Y}(\mathrm{t})$ is the VS destruction of primary sludge at time $\mathrm{t}$; 380 is theoretical value of biochemical methane potential under the standard conditions $\left(25^{\circ} \mathrm{C}, 1\right.$ atm $)\left(\mathrm{L} \mathrm{CH}_{4} / \mathrm{kg}\right.$ TCOD $)$; $\mathrm{R}_{\mathrm{SS}}$ is the ratio of VS to TCOD in the primary sludge (i.e. 0.70 in this work).

The degradation extent ( $\left.\mathrm{Y}_{0}\right)$ of primary sludge was evaluated using $\mathrm{B}_{0}$, by Eq. (3) [22]:

$\mathrm{Y}_{0}=\mathrm{B}_{0} / 380 \times \mathrm{R}_{\mathrm{SS}}$

where $\mathrm{B}_{0}$ is biochemical methane potential ( $\mathrm{L} \mathrm{CH}_{4} / \mathrm{kg} \mathrm{VS}$ ).

\section{Results}

\subsection{Overall performance of anaerobic digestion}

\subsubsection{Impact of ZVI on biochemical methane production from primary sludge}

To investigate the effect of ZVI on methane production from primary sludge in anaerobic digester, BMP test with and without ZVI addition was conducted and lasted for $50 \mathrm{~d}$. The biochemical methane production and digestion time was recorded in Fig. 1. In general, the cumulative anaerobic methane production from primary sludge in each case reached a stationary level after the 50 days' BMP test period, indicating that the complete anaerobic digestion has been achieved. By adding ZVI at the studied three levels (i.e. 1,4 and $20 \mathrm{~g} / \mathrm{L})$ in anaerobic digester, more $(\mathrm{p}<0.05)$ methane was produced from primary sludge than the control (i.e. $0 \mathrm{~g} / \mathrm{L}$ ) during the whole period. The maximal biochemical methane production of $439 \pm 5 \mathrm{~L} \mathrm{CH}_{4} / \mathrm{kg}$ VS (mean $\pm 95 \%$ confidence interval) was achieved at ZVI of $4 \mathrm{~g} / \mathrm{L}$, while only $345 \pm 2 \mathrm{~L} \mathrm{CH}_{4} / \mathrm{kg}$ VS was produced in the case of no-ZVI dosage, representing a relative increase of $26.9 \pm 0.1 \%$. This revealed that $4 \mathrm{~g} / \mathrm{L}$ was the optimum ZVI concentration in this study and ZVI could effectively enhance methane production during anaerobic digestion of primary sludge. 
(Position for Fig. 1)

Methane production reflected the VS destruction of primary sludge in anaerobic digestion (see Eq.(2)), which was shown in Fig. 2. Aligning with methane production data, the VS destruction of primary sludge showed a similar trend. ZVI at all levels (1, 4 and $20 \mathrm{~g} / \mathrm{L})$ played a driving role in VS destruction of primary sludge during the whole BMP test period. The maximum VS destruction of $81.3 \pm 1.4 \%$ over the 50 days anaerobic digestion time was achieved at ZVI of $4 \mathrm{~g} / \mathrm{L}$, while only $64.0 \pm 1.1 \%$ of primary sludge without ZVI addition was degraded in the same period, representing a relative increase of $26.9 \pm 0.1 \%$. This revealed that ZVI is effective in improving VS destruction of primary sludge in anaerobic digestion, thereby reducing the corresponding sludge disposal and transport cost.

(Position for Fig. 2)

\subsubsection{Impact of ZVI on dewaterability of anaerobically digested sludge}

Anaerobic digestion is normally applied to stabilise sludge. However, the dewaterability of the anaerobically digested sludge is generally not good, which increases the sludge bulk [23]. To investigate the effect of ZVI on dewaterability of anaerobically digested sludge, the capillary suction time (CST) of anaerobically digested sludge with and without ZVI addition was measured. At ZVI of 0, 1, 4 and $20 \mathrm{~g} / \mathrm{L}$, the CST of anaerobically digested sludge was $100 \pm 3,89 \pm 2,63 \pm 1$ and $83 \pm 1 \mathrm{~s}$, respectively. It indicated that ZVI addition resulted in faster $(\mathrm{p}<0.05)$ dewaterability of anaerobically digested sludge. 


\subsection{Model based analysis}

The experimental data of cumulative anaerobic methane production from primary sludge throughout the 50 days' test were fit to one substrate model and the result was shown in Fig. 3. It was observed that the model captured the test data well $\left(\mathrm{R}^{2}>0.95\right.$ in all cases).

(Position for Fig. 3)

Based on the one substrate model, two key parameters (i.e. hydrolysis rate $(\mathrm{k})$ and biochemical methane potential $\left(\mathrm{B}_{0}\right)$ ) of primary sludge with and without ZVI addition were determined and summarized in Table 2. In general, ZVI at the studied levels (i.e. 1, 4 and $20 \mathrm{~g} / \mathrm{L}$ ) significantly increased $(\mathrm{p}<0.05) \mathrm{k}$ of primary sludge in anaerobic digester in comparison to that with no-ZVI dosage. When ZVI concentrations were between 4 and $20 \mathrm{~g} / \mathrm{L}$, the highest increase in $\mathrm{k}$ was achieved, which was determined as approximately $38 \%$ (from 0.29 to $0.40 \mathrm{~d}^{-1}$ ) compared to that without ZVI. Similarly, ZVI also had a positive effect $(\mathrm{p}<0.05)$ on $\mathrm{B}_{0}$ of primary sludge in anaerobic digester, which was enhanced by $10-26 \%$ in comparison to that with no-ZVI dosage (i.e. from 336 to $368-422 \mathrm{~L} \mathrm{CH}_{4} / \mathrm{kg}$ VS) with the highest increase of $\mathrm{B}_{0}$ achieved at ZVI of $4 \mathrm{~g} / \mathrm{L}$. This is in accordance with the most methane production observed over the whole BMP tests period at ZVI of $4 \mathrm{~g} / \mathrm{L}$ (see Fig. 1). Correspondingly, the degradation extent $\left(\mathrm{Y}_{0}\right)$ of primary sludge increased from 0.62 to $0.68-0.78$ as well after adding ZVI (Table 2). This trend was also clearly demonstrated in Fig. 4 , which showed the $95 \%$ confidence regions of $\mathrm{B}_{0}$ and $\mathrm{k}$ in all cases. Compared to the primary sludge in anaerobic digester without ZVI addition, the confidence regions at different ZVI concentrations (1-20 g /L) moved to the right and upward, indicating both $\mathrm{k}$ and $\mathrm{B}_{0}$ of primary sludge were enhanced by adding ZVI. 
(Position for Table 2 and Fig. 4)

\section{Discussion}

This study revealed for the first time that anaerobic digestion of primary sludge by adding ZVI can combine the benefits of more methane production with improved dewaterability to achieve sludge reduction. This was experimentally demonstrated by lab-scale BMP tests with and without ZVI addition.

Different from the toxicity of NZVI (nanoscale Fe0) to bacterial [24], ZVI (millimeter scale Fe0) here promoted methane production from primary sludge by $26.9 \%$, which was due to the increased $\mathrm{k}$ and $\mathrm{B}_{0}$, as revealed in the model based analysis. The increased activities of several key enzymes related to hydrolysis after adding ZVI [14] might contribute to the enhanced k. Several publications have reported that ZVI could decrease the oxidation-reduction potential (ORP) of anaerobic digester, creating a more favorable environment for anaerobic biological processes [13, 25], thereby enhancing anaerobic decomposition of complex organics and methanogenesis [26, 27]. Moreover, ZVI could be readily utilized as an electron donor for methanogenesis [12]. Therefore, ZVI-addition could also increase the $\mathrm{B}_{0}$ from primary sludge.

In this study, $35 \mathrm{mg} / \mathrm{L} \mathrm{Fe}^{2+}$ release was observed at $4 \mathrm{~g} \mathrm{ZVI} / \mathrm{L}$. These $\mathrm{Fe}^{2+}$ can be recycled to bioreactor from anaerobic digestion liquor and further oxidized to $\mathrm{Fe}^{3+}$, which would remove phosphorus via the generation of $\mathrm{FePO}_{4}$ precipitation. On the other hand, the high dosage of ZVI does not mean the great consumption, because the redundant ZVI particles could be recovered and recycled [28].

In existing wastewater treatment plants (WWTPs), PS is often mixed and anaerobic digested 
together with another major sludge stream (i.e. WAS). The previous study demonstrated that ZVI was also able to enhance anaerobic methane production from WAS [14]. This indicated that ZVI could be added to the PS and WAS containing anaerobic digester to enhance methane production in WWTPs. However, different from the highest performance of anaerobic methane production from WAS at ZVI of $20 \mathrm{~g} / \mathrm{L}$ [14], the highest methane production from PS was obtained at ZVI of $4 \mathrm{~g} / \mathrm{L}$, which might be attributed to the different sludge characteristics. WAS is the sludge produced by biological process and it mainly contains biomass and extracellular polymeric substances (EPS) [16, 29-31]. In contrast, PS is the sludge composed of settleable solids (e.g., feces, vegetables, etc) removed from raw wastewater in primary settler. It contained more easily biodegradable organic matter compared to that of WAS [17]. Therefore, PS owns different biodegradation characteristics from WAS [32]. This was similar to the previous report, in which free nitrous acid (FNA) at the dosage of 1.0-2.0 $\mathrm{mg} \mathrm{HNO}_{2}-\mathrm{N} / \mathrm{L}$ had a negative effect on methane production from PS while it enhanced methane production from WAS by $13-27 \%$ under the same dosage $[6,17]$.

The other potential impact of ZVI was the improvement of the dewaterability in the digested sludge. Normally, water was impacted by many biological macromolecule substances (e.g. protein and lipid) forming a loose but highly hydrated capsule around the surface of sludge, which lead to sludge aggregates not easily compressed [33]. ZVI likely make more biological macromolecule substances degrade, resulting in the release of much interstitial water, thereby enhancing the dewaterability of digested sludge. In addition, the previous study showed that the accumulated hydrolysates contributed to the low dewaterability [34]. ZVI could increase hydrolysis rate and make the biodegradable substances in sludge degrade more rapidly, avoiding the accumulation of hydrolysates.

However, it should be noted that this work is merely a proof-of-concept research to evaluate 
the feasibility of the proposed ZVI technology. The experimental results were acquired via the BMP batch tests in the study and the CST-dewaterability method applied in this batch study only provides a qualitative measure. Therefore, continuous tests will be required in the future to quantitatively assess the effect of ZVI on the dewaterability of the anaerobically digested sludge using laboratory centrifuge test or belt filter test, which can determine the dry solids content of the dewatered sludge. Also, further studies should also be conducted to further reveal the mechanisms behind the improved methane production.

The enhanced anaerobic methane production and dewaterability of digested sludge translates to lower overall costs for sludge disposal. To further elucidate the applicability of the proposed ZVI technology regarding its economic potential, the experimental results acquired at $4 \mathrm{~g} \mathrm{ZVI/L}$ were used to conduct the economic evaluation of the ZVI technology in a full-scale WWTP with a 400,000 population equivalent (PE) via a desktop scaling-up study. The results are shown in Table 3, which shows that the saving can be $\$ 1,350,000 /$ year after adding ZVI into the anaerobic digester. The saving is mainly from the benefit due to the enhanced methane production from primary sludge and the decreased sludge transport and disposal costs. It should be noted that the improved dewaterability and the enhanced methane production from secondary sludge were not considered in this analysis. More savings can be achieved after considering them.

From the above, the proposed ZVI-addition technology was demonstrated in Fig. 5. ZVI could be added to the anaerobic digester to enhance methane production from both PS and WAS. A small amount of ZVI was oxidized to $\mathrm{Fe}^{2+}$, which was then returned to the mainstream bioreactor together with the anaerobic digestion liquor. In the mainstream bioreactor, the $\mathrm{Fe}^{2+}$ was further oxidized to $\mathrm{Fe}^{3+}$, which is then used for phosphorus removal process. The enhanced dewaterability of anaerobically digested sludge will also be achieved. 
(Position for Fig. 5)

\section{Conclusions}

Laboratory biochemical methane potential (BMP) tests were performed to evaluate the effect of ZVI on anaerobic methane production from primary sludge. The addition of ZVI at the studied three levels (i.e. 1, 4 and $20 \mathrm{~g} / \mathrm{L}$ ) significantly enhanced anaerobic methane production from primary sludge by $12-27 \%$ (from $345 \pm 2$ to $386-439 \mathrm{~L} \mathrm{CH} 4 / \mathrm{kg}$ VS) and achieved a digested sludge with a better dewaterability, indicating that ZVI could be added to the PS and WAS containing anaerobic digester to enhance methane production in WWTPs. The ZVI increases both hydrolysis rate and biochemical methane potential of primary sludge in anaerobic digestion. Overall, the ZVI technology is potentially economically favourable through enhancing methane production and reducing sludge disposal costs.

\section{Acknowledgements}

The authors acknowledge the Australian Research Council (ARC) for funding support through the Discovery Early Career Researcher Award (DE160100667) and Discovery Project (DP170102812) awarded to Dr. Qilin Wang.

\section{References}

[1] C. Eskicioglu, A. Prorot, J. Marin, R.L. Droste, K.J. Kennedy, Synergetic pretreatment of sewage sludge by microwave irradiation in presence of $\mathrm{H}_{2} \mathrm{O}_{2}$ for enhanced anaerobic digestion, Water Res. 42(18) (2008) 4674-4682.

[2] J. Abelleira-Peraira, S. Perez-Elvira, J. Sanchez-Oneto, R. Cruz, J. Portela, E. Nebot, 
Enhancement of methane production in mesophilic anaerobic digestion of secondary sewage sludge by advanced thermal hydrolysis pretreatment, Water Res. 71 (2015) 330-340.

[3] P. Foladori, G. G. Andreottola, G. Ziglio, Sludge Reduction Technologies in Wastewater Treatment Plants, IWA Publishing, London (2010).

[4] X. Zhou, Q. Wang, G. Jiang, Enhancing methane production from waste activated sludge using a novel indigenous iron activated peroxidation pre-treatment process, Bioresour. Technol. 182 (2015) 267-271.

[5] Q. Wang, W. Wei, Y. Gong, Q. Yu, Q. Li, J. Sun, Z. Yuan, Technologies for reducing sludge production in wastewater treatment plants: state of the art, Sci. Total Environ. 587 (2017) $510-521$.

[6] Q. Wang, L. Ye, G. Jiang, P. Jensen, D. Batstone, Z. Yuan, Free nitrous acid (FNA)-based pre-treatment enhances methane production from waste activated sludge, Environ. Sci. Technol. 47(20) (2013) 11897-11904.

[7] C.D. Muller, M. Abu-Orf, J.T. Novak, The effect of mechanical shear on mesophilic anaerobic digestion, In: WEFTEC, 76th Annual Conference \& Exhibition: Los Angeles, USA (2003).

[8] I. Doğan, F.D. Sanin, Alkaline solubilization and microwave irradiation as a combined sludge disintegration and minimization method, Water Res. 43(8) (2009) 2139-2148.

[9] Y.C. Song, S.J. Kwon, J.H. Woo, Mesophilic and thermophilic temperature co-phase anaerobic digestion compared with single-stage mesophilic- and thermophilic digestion of sewage sludge, Water Res. 38(7) (2004) 1653-1662.

[10] H.J. Roman, J.E. Burgess, B.I. Pletschke, Enzyme treatment to decrease solids and improve digestion of primary sewage sludge, Afr. J Biotechnol. 5(10) (2006) 963-967.

[11] Q. Wang, X. Hao, Z. Yuan, Towards energy positive wastewater treatment by sludge treatment 
using free nitrous acid. Chemosphere 144 (2016) 1869-1873.

[12] S. Karri, R. Sierra-Alvarez, J.A. Field, Zero valent iron as an electron-donor for methanogenesis and sulfate reduction in anaerobic sludge, Biotechnol. Bioeng. 92(7) (2005) 810-819.

[13] Y. Liu, Y. Zhang, X. Quan, Y. Li, Z. Zhao, X. Meng, S. Chen, Optimization of anaerobic acidogenesis by adding $\mathrm{Fe}^{0}$ powder to enhance anaerobic wastewater treatment, Chem. Eng. J 192 (1) (2012) 179-185.

[14] Y. Feng, Y. Zhang, X. Quan, S. Chen, Enhanced anaerobic digestion of waste activated sludge digestion by the addition of zero valent iron, Water Res. 52 (2014) 242-250.

[15] H. Ge, P.D. Jensen, D.J. Batstone, Pre-treatment mechanisms during thermophilic- mesophilic temperature phased anaerobic digestion of primary sludge, Water Res. 44(1) (2010) 123-130.

[16] H. Carrère, C. Dumas, A. Battimelli, D.J. Batstone, J.P. Delgenès, J.P. Steyer, I. Ferrer, Pretreatment methods to improve sludge anaerobic degradability: A review, J Hazard Mater. 183(1) (2010) 1-15.

[17] T. Zhang, Q. Wang, L. Ye, Z. Yuan, Effect of free nitrous acid pre-treatment on primary sludge biodegradability and its implications, Chem. Eng. J 290 (2016) 31-36.

[18] W. Wei, X. Zhou, G. Xie, H. Duan, Q. Wang, A novel free ammonia based pretreatment technology to enhance anaerobic methane production from primary sludge, Biotechnol. Bioeng. 114 (10) (2017) 2245-2252.

[19] W. Wei, X. Zhou, D. Wang, J. Sun, Q. Wang, Free ammonia pre-treatment of secondary sludge significantly increases anaerobic methane production, Water Res. 118 (2017) 12-19.

[20] APHA, Standard Methods for Water and Wastewater Examination, American Public Health Association, Washington, DC (2005). 
[21] D.J. Batstone, S. Tait, D. Starrenburg, Estimation of hydrolysis parameters in full-scale anaerobic digesters, Biotechnol. Bioeng. 102 (5) (2009) 1513-1520.

[22] Metcalf, Eddy, Wastewater Engineering: Treatment and Reuse, McGraw- Hill Inc. (2003).

[23] A.J. Feitz, J. Guan, T.D. Waite, Size and structure effects on centrifugal dewatering of digested sewage sludge, Water Sci. Technol. 44 (2-3) (2001) 427-435.

[24] J.W. Chen, Z.M. Xiu, G.V. Lowry, P.J.J. Alvarez, Effect of natural organic matter on toxicity and reactivity of nano-scale zero-valent iron, Water Res. 45 (2011) 1995-2001.

[25] E. Alkaya, G.N. Demirer, Anaerobic acidification of sugarbeet processing wastes: effect of operational parameters, Biomass Bioenerg. 35 (1) (2011) 32-39.

[26] Y. He, J.-F. Gao, F.-Q. Feng, C. Liu, Y.-Z. Peng, S.-Y. Wang, The comparative study on the rapid decolorization of azo, anthraquinone and triphenylmethane dyes by zero-valent iron, Chem. Eng. J. 179 (2012) 8-18.

[27] J. Zhang, Y. Zhang, X. Quan, Y. Liu, X. An, S. Chen, H. Zhao, Bioaugmentation and functional partitioning in a zero valent iron-anaerobic reactor for sulfatecontaining wastewater treatment, Chem. Eng. J. 174 (2011) 159-165.

[28] K. Song, X. Zhou, Y. Liu, G. Xie, D. Wang, T. Zhang, C. Liu, P. Liu, B. Zhou, Q. Wang, Improving dewaterability of anaerobically digested sludge by combination of persulfate and zero valent iron, Chem. Eng. J. 295 (2016) 436-442.

[29] X. Zhou, W. Jin, C. Sun, S. Gao, C. Chen, Q. Wang, S. Han, R. Tu, M. Latif, Q. Wang, Microbial degradation of N,N-dimethylformamide by Paracoccus sp. strain DMF-3 from activated sludge. Chem. Eng. J. 343 (2008) 324-330.

[30] Q. Wang, H. Duan, W. Wei, B. Ni, A. Laloo, Z. Yuan, Achieving stable mainstream nitrogen removal via the nitrite pathway by sludge treatment using free ammonia. Environ. Sci. Technol. 
51 (17) (2017), 9800-9807.

[31] Q. Wang, A roadmap for achieving energy-positive sewage treatment based on sludge treatment using free ammonia. ACS Sustain. Chem. Eng. 5 (2017) 9630-9633.

[32] H. Wu, J. Gao, D. Yang, Q. Zhou, W. Liu, Alkaline fermentation of primary sludge for short-chain fatty acids accumulation and mechanism, Chem. Eng. J 160 (2010) 1-7.

[33] N. Katsiris, A. Kouzeli-Katsiri, Bound water content of biological sludges in relation to filtration and dewatering, Water Res. 21 (11) (1987) 1319-1327.

[34] F. Lü, Q. Zhou, D. Wu, T. Wang, L. Shao, P. He, Dewaterability of anaerobic digestate from food waste: Relationship with extracellular polymeric substances, Chem. Eng. J 262 (2015) 932-938. 


\section{List of Tables and Figures}

Table 1. Main characteristics of the substrate and inoculums used in the tests.

Table 2. Estimated $\mathrm{k}, \mathrm{B}_{0}$ and $\mathrm{Y}_{0}$ at different $\mathrm{ZVI}$ concentrations using one-substrate model (with $95 \%$ confidence intervals).

Table 3. Economic analysis of the ZVI technology for enhancing methane production from primary sludge

Fig. 1. Cumulative methane production from primary sludge in anaerobic digester with and without ZVI addition. Error bars represent $95 \%$ confidence intervals.

Fig. 2. VS destruction of primary sludge in anaerobic digester with and without ZVI addition. Error bars represent $95 \%$ confidence intervals.

Fig. 3. Measured and fitted anaerobic methane production from primary sludge (symbols represent experimental measurements and lines represent simulated values). Inset shows an enlargement of the first 10 days.

Fig. 4. The $95 \%$ confidence regions of hydrolysis rate $\left(k, d^{-1}\right)$ and biochemical methane potential $\left(\mathrm{B}_{0}, \mathrm{~L} \mathrm{CH}_{4} / \mathrm{kg} \mathrm{VS}\right)$ of primary sludge in anaerobic digester with and without $\mathrm{ZVI}$ addition. 
Fig. 5. Conceptual graph of the proposed ZVI-addition technology for improving methane production in a wastewater treatment plant.

\section{Table 1}

Main characteristics of the substrate and inoculums used in the tests.

\begin{tabular}{ccc}
\hline Parameter & Substrate $^{\mathrm{a}}$ & Inoculum $^{\mathrm{a}}$ \\
Total Solids (TS) $(\mathrm{g} / \mathrm{L})$ & $37.2 \pm 0.5$ & $26.6 \pm 0.2$ \\
Volatile Solids (VS) $(\mathrm{g} / \mathrm{L})$ & $28.8 \pm 0.5$ & $19.0 \pm 0.2$ \\
Total Chemical Oxygen Demand (TCOD) (g/L) & $40.9 \pm 0.5$ & $28.5 \pm 0.2$ \\
Soluble Chemical Oxygen Demand (SCOD) (g/L) & $3.3 \pm 0.1$ & $0.5 \pm 0.1$ \\
$\mathrm{pH}$ & $5.9 \pm 0.1$ & $7.4 \pm 0.1$ \\
\hline
\end{tabular}

${ }^{a}$ Indicate standard errors based on triplicate measurements. 
Table 2

Estimated $\mathrm{k}, \mathrm{B}_{0}$ and $\mathrm{Y}_{0}$ at different ZVI concentrations using an one-substrate model (with $95 \%$ confidence intervals).

\begin{tabular}{cccc}
\hline & \multicolumn{3}{c}{ Parameters } \\
\cline { 2 - 4 } $\mathrm{ZVI}(\mathrm{g} / \mathrm{L})$ & $\mathrm{k}\left(\mathrm{d}^{-1}\right)$ & $\mathrm{B}_{0}\left(\mathrm{~L} \mathrm{CH}_{4} / \mathrm{kg} \mathrm{VS}\right)$ & $\mathrm{Y}_{0}$ \\
\hline 0 (i.e. control) & $0.29 \pm 0.02$ & $336 \pm 5$ & $0.62 \pm 0.01$ \\
1 & $0.33 \pm 0.02$ & $368 \pm 6$ & $0.68 \pm 0.01$ \\
4 & $0.40 \pm 0.03$ & $422 \pm 6$ & $0.78 \pm 0.01$ \\
\hline
\end{tabular}




\section{Table 3}

Economic analysis of the ZVI technology for enhancing methane production from primary sludge

\begin{tabular}{|c|c|}
\hline General parameter & Values \\
\hline Size of the WWTP (Population equivalent - PE) & 400,000 \\
\hline Influent Chemical Oxygen Demand (COD) (mg/L) & \\
\hline Influent Biochemical Oxygen Demand (BOD) (mg/L) & $0^{\mathrm{a}}$ \\
\hline Influent Total Kjeldahl Nitrogen (TKN) (mg N/L) & $55^{\mathrm{a}}$ \\
\hline Influent ammonium nitrogen (mg N/L) & $35^{\mathrm{a}}$ \\
\hline Influent total suspended solids (mg/L) & $200^{\mathrm{a}}$ \\
\hline Influent volatile suspended solids (mg/L) & $180^{\mathrm{a}}$ \\
\hline Decay coefficient of the heterotrophic biomass $\left(\mathrm{d}^{-1}\right)$ & $0.2^{\mathrm{a}}$ \\
\hline Decay coefficient of the nitrifying biomass $\left(\mathrm{d}^{-1}\right)$ & $0.1^{\mathrm{a}}$ \\
\hline Yield coefficient of the heterotrophic biomass (g COD/g COD) & $0.625^{\mathrm{a}}$ \\
\hline Yield coefficient of the nitrifying biomass $(\mathrm{g} \mathrm{COD} / \mathrm{g} \mathrm{N})$ & $0.24^{\mathrm{a}}$ \\
\hline Fraction of inert COD generated in biomass decay (g COD/g COD) & $0.2^{\mathrm{a}}$ \\
\hline Mixed liquor suspended solid concentration in the bioreactor $(\mathrm{mg} / \mathrm{L})$ & 4,000 \\
\hline Mixed liquor volatile suspended solid concentration in the bioreactor $(\mathrm{mg} / \mathrm{L})$ & 3,200 \\
\hline Sludge retention time (SRT) in the bioreactor of the WWTP (d) & 15 \\
\hline Mixed liquor suspended solid concentration in the bioreactor (mg/L) & $4,000^{\mathrm{a}}$ \\
\hline Mixed liquor volatile suspended solid concentration in the bioreactor $(\mathrm{mg} / \mathrm{L})$ & $3,200^{\mathrm{a}}$ \\
\hline Solids content in thickened sludge & $5 \%$ \\
\hline Solids content in dewatered sludge & $15 \%$ \\
\hline
\end{tabular}


Hydraulic retention time in the anaerobic digester (d)

Methane calorific value $\left(\mathrm{kwh} / \mathrm{kgCH}_{4}\right)$

Power price $(\$ / \mathrm{kwh})$

0.15

Conversion efficiency of methane to heat

Conversion efficiency of methane to power

Cost of sludge transport and disposal (\$/wet tonne)

Primary sludge produced and fed to anaerobic digester

(kilotonne TS/year)

Primary sludge produced and fed to anaerobic digester

(kilotonne VS/year)

WAS produced and fed to anaerobic digester (kilotonne

TS/year)

WAS produced and fed to anaerobic digester (kilotonne VS

Control system /year)

without ZVI Degradation of primary sludge in anaerobic digester (on a dry VS basis)

Degradation of WAS in anaerobic digester (on a dry VS $30 \%^{\mathrm{a}}$ basis)

Remaining sludge after anaerobic digestion (kilotonne

TS/year)

Remaining sludge after anaerobic digestion (kilotonne

VS/year) 
Methane production (tonne $\mathrm{CH}_{4}$ /year)

Energy production from methane ( $\mathrm{kWh} /$ year)

$25,000,000$

Benefit due to energy production from methane $(\$ /$ year $) \quad+\mathbf{3 , 7 5 0 , 0 0 0}$

Cost of sludge transport and disposal (\$/year)

Primary sludge produced and fed to anaerobic digester

(kilotonne TS/year)

Primary sludge produced and fed to anaerobic digester

(kilotonne VS/year)

WAS produced and fed to anaerobic digester (kilotonne

TS/year)

WAS produced and fed to anaerobic digester (kilotonne VS

/year)

ZVI concentration $(\mathrm{g} / \mathrm{L})$

4

System with ZVI

Degradation of primary sludge in anaerobic digester (on a

dry VS basis)

$81 \%^{\mathrm{b}}$

Degradation of WAS in anaerobic digester (on a dry VS

basis)

Remaining sludge after anaerobic digestion (kilotonne

TS/year)

Remaining sludge after anaerobic digestion (kilotonne

VS/year)

ZVI-associated cost after considering ZVI recovery 
(\$/year)

Energy production from methane (kWh/year)

$31,000,000$

Benefit due to energy production from methane $(\$ / y e a r) \quad+4,650,000$

Cost of sludge transport and disposal (\$/year) $\quad-1,200,000$

Annual saving (\$/year)

$1,350,000$

${ }^{\mathrm{a}}$ Personal communication with industry partners and refer to Metcalf and Eddy [22].

${ }^{b}$ Based on this study 


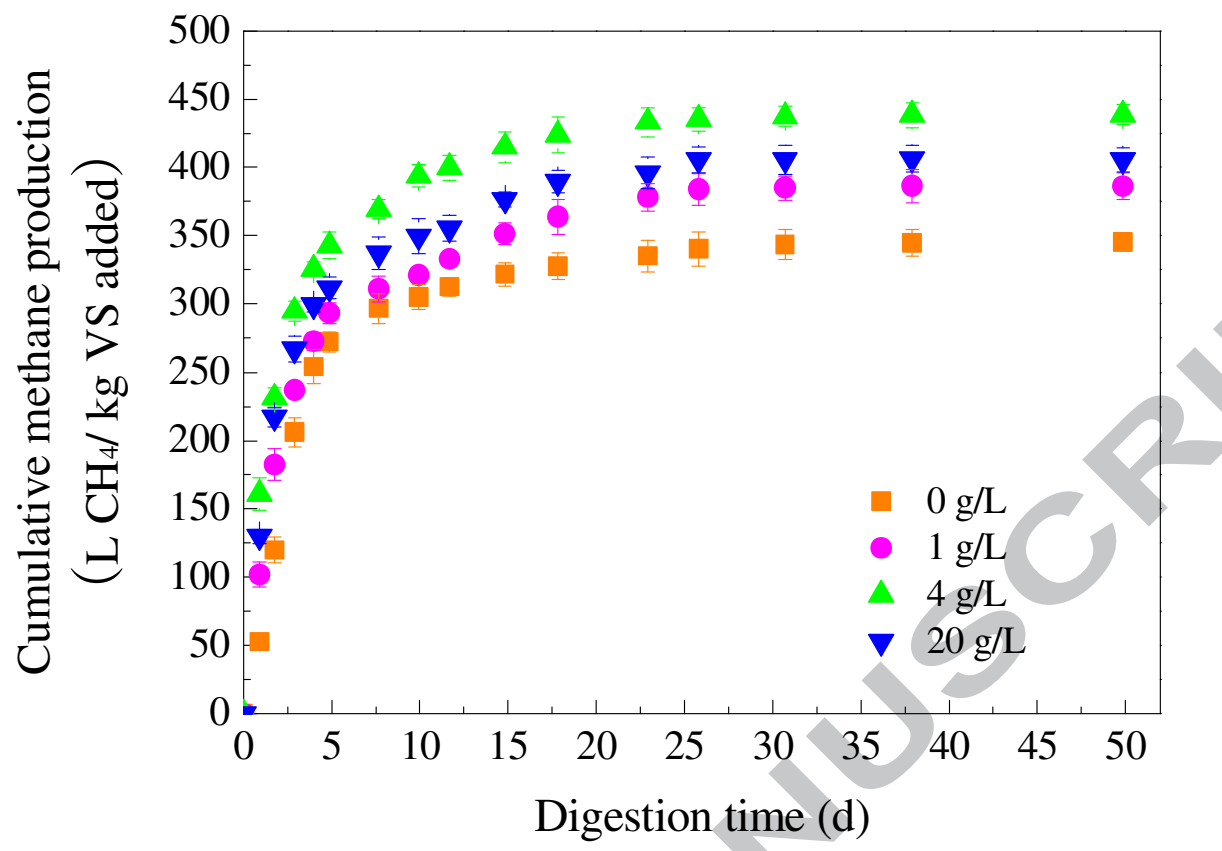

Fig. 1. Cumulative methane production from primary sludge in anaerobic digester with and without ZVI addition. Error bars represent $95 \%$ confidence intervals. 


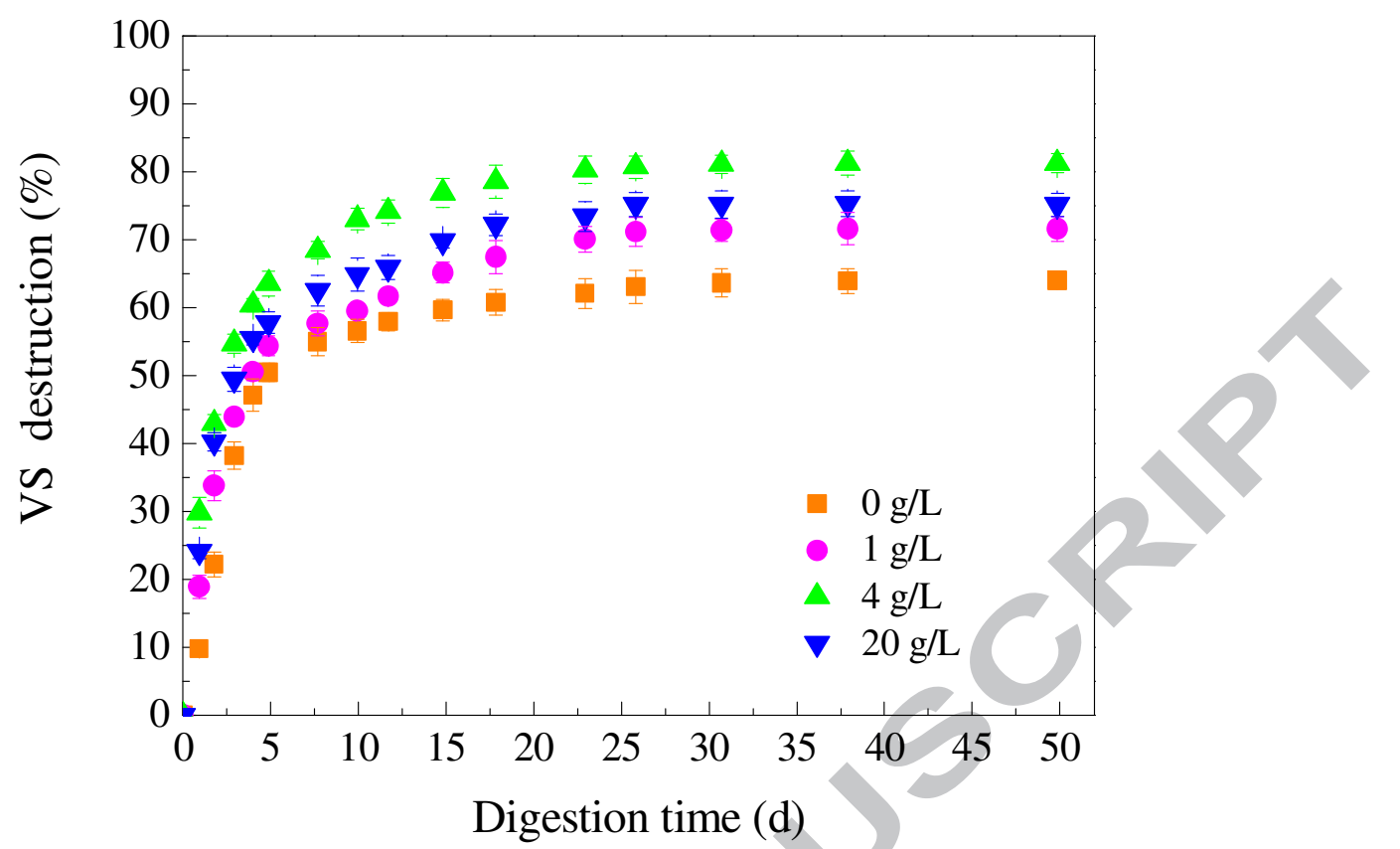

Fig. 2. VS destruction of primary sludge in anaerobic digester with and without ZVI addition. Error bars represent $95 \%$ confidence intervals. 


\section{ACCEPTED MANUSCRIPT}

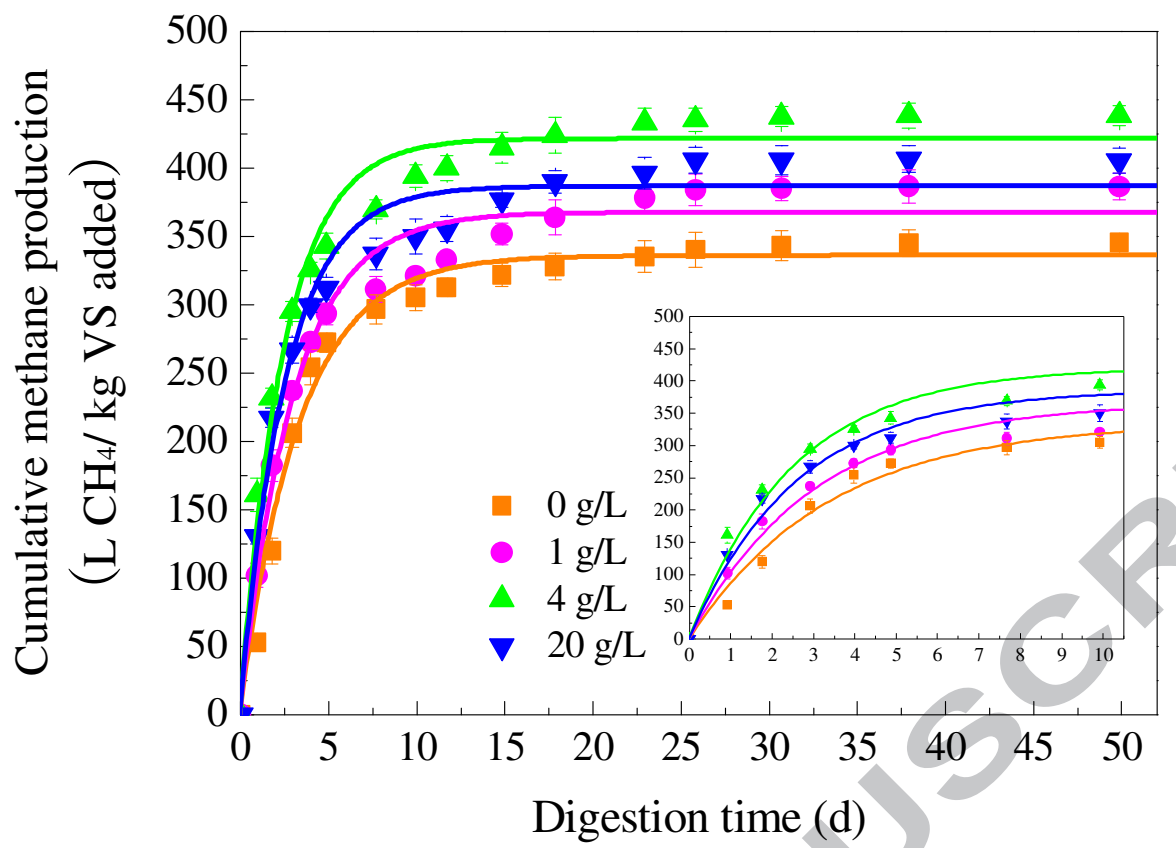

Fig. 3. Measured and fitted anaerobic methane production from primary sludge (symbols represent experimental measurements and lines represent simulated values). Inset shows an enlargement of the first 10 days. 


\section{ACCEPTED MANUSCRIPT}

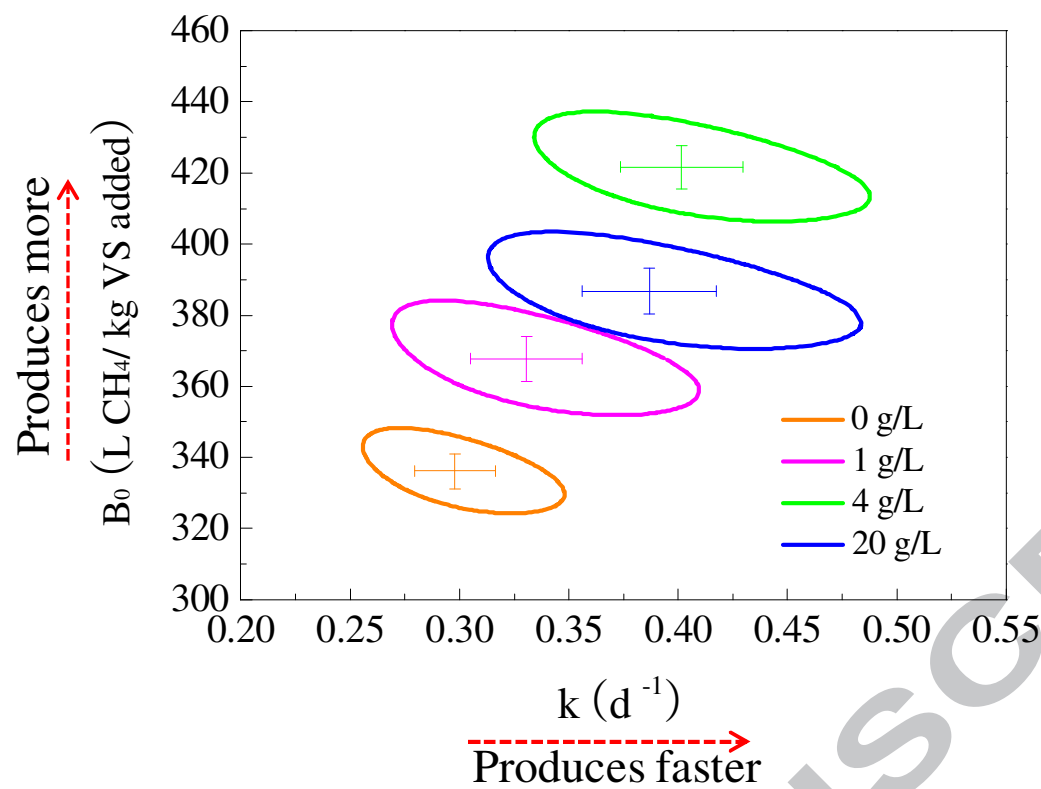

Fig. 4. The $95 \%$ confidence regions of hydrolysis rate $\left(\mathrm{k}, \mathrm{d}^{-1}\right)$ and biochemical methane potential $\left(\mathrm{B}_{0}, \mathrm{~L} \mathrm{CH}_{4} / \mathrm{kg} \mathrm{VS}\right)$ of primary sludge in anaerobic digester with and without $\mathrm{ZVI}$ addition. 


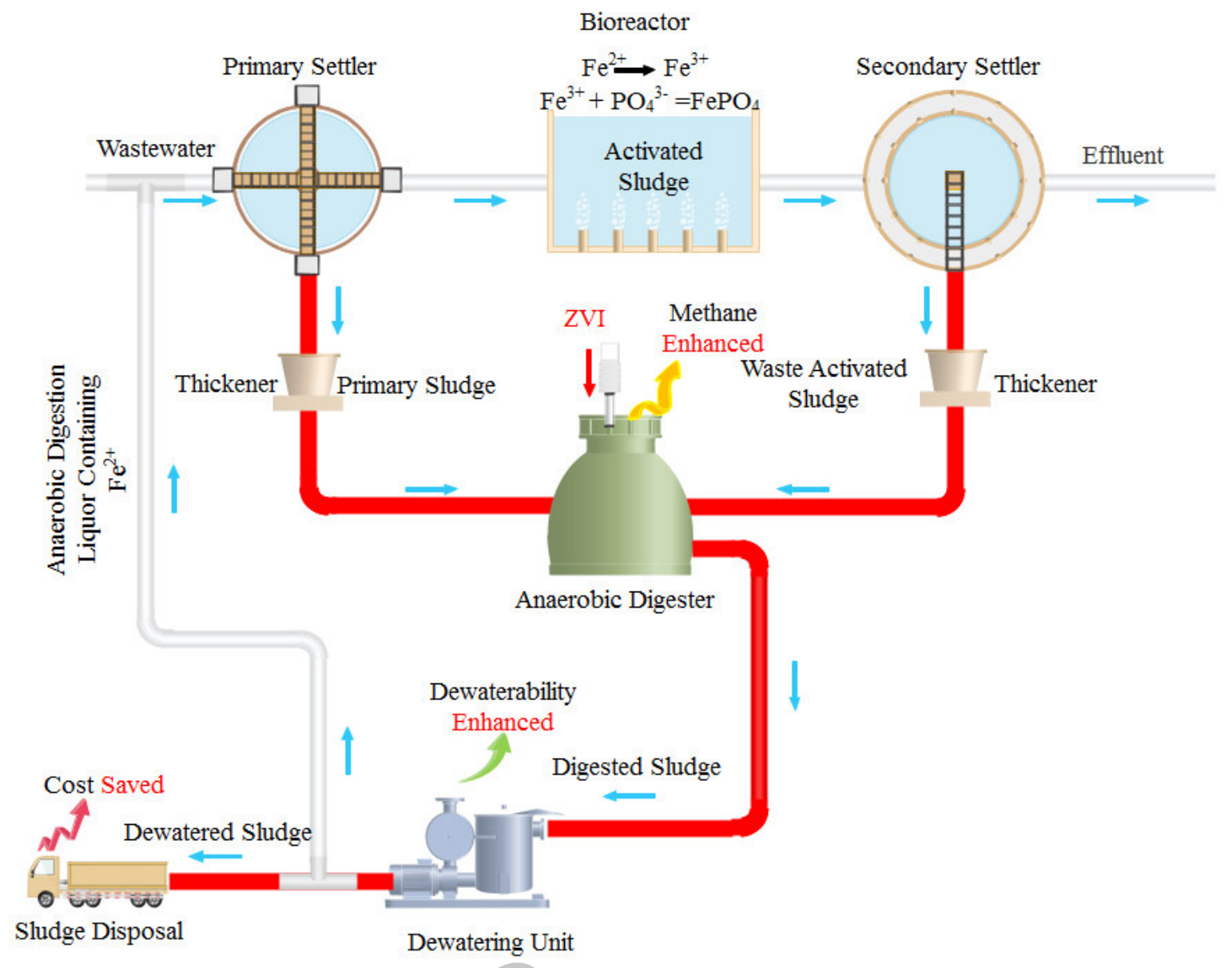

Fig. 5. Conceptual graph of the proposed ZVI-addition technology for improving methane production in a wastewater treatment plant. 


\section{Graphical Abstract}

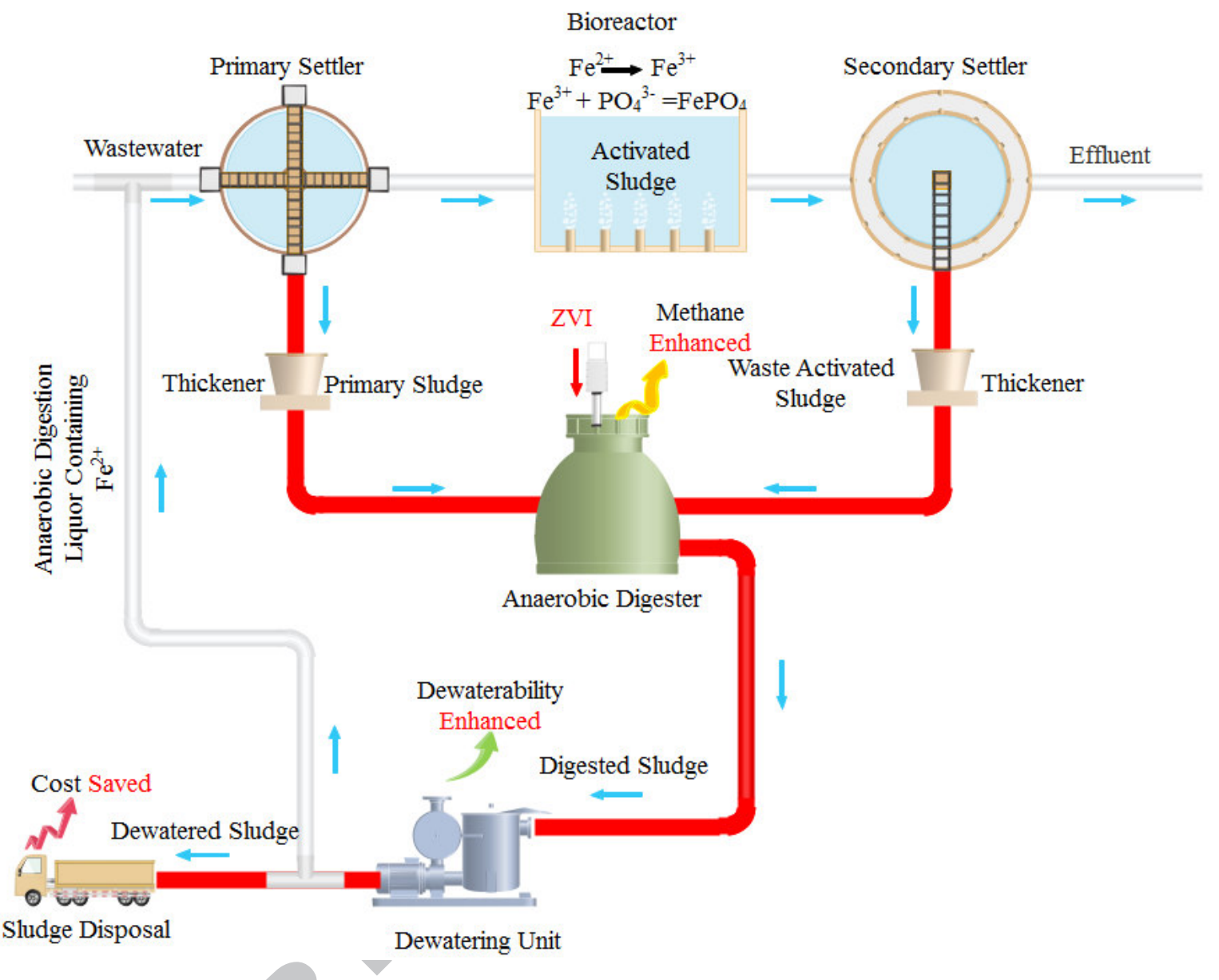




\section{Highlights}

- ZVI enhanced anaerobic methane production from the PS

- The increase in $\mathrm{k}$ and $\mathrm{B}_{0}$ supported the enhanced methane results

- $\quad$ ZVI achieved a digested sludge with a better dewaterability

- ZVI technology is economically favourable through reducing sludge disposal costs 


\section{Accepted Manuscript}

Zero valent iron enhances methane production from primary sludge in anaerobic digestion

Wei Wei, Zhengqing Cai, Jie Fu, Guo-Jun Xie, Ang Li, Xu Zhou, Bing-Jie Ni, Dongbo Wang, Qilin Wang

PII:

S1385-8947(18)31199-9

DOI: https://doi.org/10.1016/j.cej.2018.06.160

Reference:

CEJ 19371

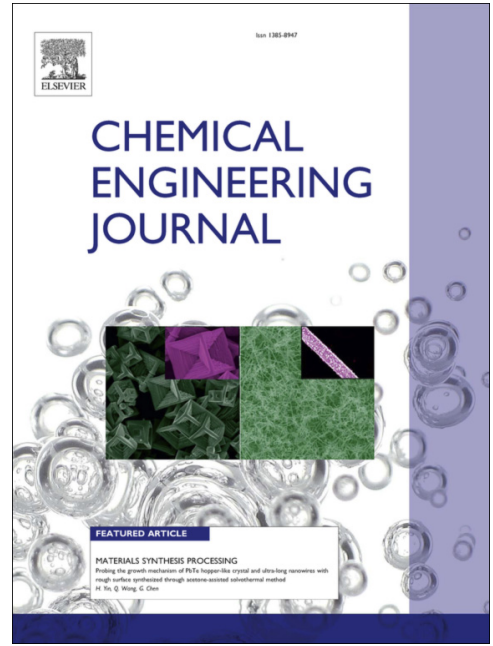

To appear in:

Chemical Engineering Journal

Received Date:

1 May 2018

Revised Date:

21 June 2018

Accepted Date:

24 June 2018

Please cite this article as: W. Wei, Z. Cai, J. Fu, G-J. Xie, A. Li, X. Zhou, B-J. Ni, D. Wang, Q. Wang, Zero valent iron enhances methane production from primary sludge in anaerobic digestion, Chemical Engineering Journal (2018), doi: https://doi.org/10.1016/j.cej.2018.06.160

This is a PDF file of an unedited manuscript that has been accepted for publication. As a service to our customers we are providing this early version of the manuscript. The manuscript will undergo copyediting, typesetting, and review of the resulting proof before it is published in its final form. Please note that during the production process errors may be discovered which could affect the content, and all legal disclaimers that apply to the journal pertain. 